Accepted $22^{\text {nd }}$ May 2021 for publication in The Police Journal: Theory, Practice, and Principles

\title{
English Police Officers' Alcohol Consumption and Links with Organisational Job Stressors
}

\author{
Jonathan Houdmont \\ School of Medicine, University of Nottingham \\ (D)https://orcid.org/0000-0001-5174-2619 \\ Liza Jachens \\ Department of Psychology, Webster University \\ (D)https://orcid.org/0000-0003-2581-285X
}




\begin{abstract}
This study describes alcohol consumption and examines associations with organisational job stressors among female $(n=493)$ and male $(n=707)$ English police officers. Significantly fewer female than male officers reported hazardous alcohol consumption ( $32 \%$ vs. $44 \%)$ and probable harmful alcohol consumption (5\% vs. 11\%). Stressor exposure was associated with alcohol consumption among males only, with high exposure to job control, work relationships, and role clarity stressors associated with elevated odds of probable harmful alcohol consumption. Findings suggest alcohol consumption represents a concern in English policing and point to stressor-exposure reduction as a mechanism to reduce alcohol consumption.
\end{abstract}

Keywords: alcohol consumption, AUDIT-C, Management Standards, police, stress 


\section{English Police Officers' Alcohol Consumption and Links with Organisational Job Stressors}

Globally, alcohol consumption is the seventh leading risk factor for deaths and disability-adjusted life-years (Griswold et al., 2018). Alcohol consumption, even at low levels or consumed infrequently, is associated with increased risk of a range of illnesses (Yasin and Banoub, 2018). In the organisational context, alcohol consumption represents a preventable threat to various aspects of operational effectiveness including, inter alia, sickness absence and presenteeism, job performance, and work accidents (Anderson, 2012). In a wide-ranging review of the health and wellbeing of emergency responders in the United Kingdom (UK), The Royal Foundation (2020) highlighted a paucity of research on alcohol misuse and called for work to inform interventions that address the needs of emergency responders. The present study represents a response to that call with a focus on alcohol consumption in English police officers. Specifically, we set out to examine the frequency and quantity of alcohol consumption, and prevalence of hazardous and probable harmful consumption, in a large and diverse sample of police officers. In addition, we examine linkages between alcohol consumption and exposure to potentially modifiable organisational job stressors embedded within the psychosocial work environment that might provide a focus for intervention activities targeting alcohol misuse.

\section{Alcohol Consumption in UK Policing}

High rates of alcohol consumption have been observed worldwide among police officers (Syed et al., 2020), yet surprisingly little is known about consumption rates in UK policing. A small body of evidence exists concerning the prevalence of alcohol consumption among UK police officers and how this compares to policing in other national contexts. Research involving police officers from five nations whose alcohol consumption was assessed using the Alcohol Use Disorders Identification Test (AUDIT: Barbor et al., 2001) showed a mean consumption rate of 5.95 (maximum possible range 0-40) among 102 UK 
officers. This rate was higher than observed among officers from the United States (US) ( $M=$ 4.18) and Canada $(M=5.17)$, yet below rates found in Australia (7.16) and New Zealand (6.95) (Ménard et al., 2016). In all five national samples the mean rate fell below the threshold at which consumption is considered hazardous (AUDIT score $\geq 8$ ). Across the multinational sample as a whole, male officers reported significantly higher consumption (Ménard and Arter, 2014). Similar consumption rates have been observed in other US and Australian studies (Davey et al., 2000a; Violanti et al., 2011). Studies such as these provide a useful indication of mean alcohol consumption rates in policing and permit cross-national comparisons. However, two shortcomings in the UK evidence base point to the need for further investigation in this context. First, existing knowledge is based on a single sample of 102 officers. Research on a larger scale is required to generate a reliable indication of alcohol consumption in UK policing and permit stratification by socio- and occupationaldemographic groups. Second, the existing knowledge base describes only the mean alcohol consumption rate. The proportion and socio- and occupational-demographic characteristics of police officers reporting hazardous and probable harmful alcohol consumption remains unknown. This represents an important gap in the knowledge base since knowledge in this regard would help to establish whether alcohol consumption in UK policing represents an occupational health concern. Moreover, identification of at-risk groups is necessary to inform the targeting of intervention resources. In the current study we seek to extend on current knowledge by examining alcohol consumption in a large and diverse sample of UK police officers and establishing the proportion of officers reporting hazardous and probable harmful alcohol consumption whereby intervention may be warranted.

\section{Alcohol Consumption and Job Stress in UK Policing}

There exists an extensive literature going back several decades attesting to linkages between alcohol consumption and job stress in police officers, much of which hails from the 
US (e.g., Violanti et al., 1985). Viewed through the lens of general strain theory (Agnew, 1992), alcohol consumption can be regarded as a maladaptive mechanism for coping with stressor exposures that is mediated by negative affect; a contention that finds support in policing (Gibson et al., 2001; Piquero, 2005; Swatt et al., 2007). The police stress literature generally divides job stressors into two categories: operational and organisational. The former encompasses stressors specific to job content, with three types of operational stressor having been distinguished in UK policing: exposure to death and disaster (traumatic), violence and injury (routine), and sexual crime (vicarious) (Brown et al., 1999). Organisational stressors concern generic or universal characteristics found in the context of the job, such as high demands, low control, low managerial support, and poor relationships. Organisational stressors are often reported as the more problematic in policing both in the UK (Collins and Gibbs, 2003) and internationally (e.g., Carleton et al., 2020; McCreary and Thompson, 2006), possibly because they represent daily routines (Violanti et al., 2017) and "are perceived as being beyond one's control and oppressive, unnecessary and inescapable" (Chan and Anderson, 2020: 496-497).

Evidence on relations between alcohol consumption and job stressor exposure in UK policing remains limited and has produced mixed findings. Regarding operational stressors, degree of all-career exposure to critical traumatic incidents (e.g., being shot at; being threatened with a gun, knife or other weapon; seeing someone die) failed to significantly account for alcohol consumption rates among police officers drawn from five national contexts, including a small UK sample (Ménard et al., 2016). Taking the multinational sample as a whole, contrasting patterns of relations between stressor exposure and alcohol consumption were observed by gender, with critical incident exposure and social stressors showing small yet significant correlations with alcohol consumption among males only (Ménard and Arter, 2014). Among child abuse investigation unit police officers in England 
and Wales $(N=101)$, cross-sectional associations were found between the number of interviews conducted in the previous six month (with suspected perpetrators, adult survivors, and child victims) and secondary traumatic stress, which in turn was associated with use of negative coping strategies that included alcohol and drugs (Hurrell et al., 2018). Qualitative research involving UK police officers investigating child sexual exploitation found less support for a stressor-alcohol link, with few interviewees reporting use of alcohol as a coping method (Ahern et al., 2017). Similarly, in a small-scale interview study involving five UK police officers that had experienced mental health problems, a minority reported using alcohol as a mechanism for coping with stress (Edwards and Kotera, 2020).

Some UK evidence exists concerning relations between organisational job stressors and alcohol consumption. A positive association was observed between exposure to organisational job stressors and use of 'alcohol or other drugs' among a sample of 720 officers and civilian call handlers working in police call handling and dispatch centres (Galbraith et al., 2021). Organisational job stressor exposures were assessed using the UK Health and Safety Executive's ${ }^{1}$ (n.d.) Management Standards Indicator Tool, which evaluates exposure to seven dimensions of the psychosocial work environment that, if not properly managed, can lead to harm to employees and organisations. These dimensions include job demands, job control, managerial support, peer support, work relationships, role ambiguity, and change communication and consultation. Initially designed to assist organisations in meeting their legal duty in relation to psychosocial risk assessment (Cousins et al., 2004; Mackay et al., 2004), the instrument's popularity as a work environment research tool has mushroomed in recent years (Brookes et al., 2013). Police-specific reference values are available (Houdmont et al., 2012). In view of the demonstrated efficacy of the Management Standards Indicator Tool in the UK police context we used this scale in the current study to

\footnotetext{
${ }^{1}$ The government agency responsible for regulation of work-related health and safety.
} 
assess organisational job stressor exposures. A research focus on organisational job stressors is also advantageous from an intervention standpoint. Given the nature of the policing role, it can be difficult to eradicate exposure to operational stressors. In contrast, organisational stressors are more modifiable since aspects of the design, management, and organisation of work generally fall within the control of an employer.

\section{Aims of the Current Study}

Some international studies have shown elevated rates of alcohol consumption among police officers. A paucity of data on alcohol consumption in UK policing prevents conclusions on whether alcohol consumption represents an occupational health problem in this population and interventions are required to reduce consumption in at-risk groups. In response, the first aim of this study is to quantify frequency and quantity of alcohol consumption in a large and diverse sample of English police officers. Organisational stressors embedded in the psychosocial work environment have been identified as a correlate of alcohol consumption for police officers in a variety of national contexts. Demonstration of links between exposure to organisational job stressors that are receptive to modification and alcohol consumption would help inform the design and targeting of work environment adaptations as a means by which to reduce alcohol consumption. Thus, the second aim of this study is to examine the strength and direction of associations between alcohol consumption and a set of 35 organisational job stressors located within seven psychosocial work environment dimensions delineated by the UK Health and Safety Executive.

\section{Methods}

\section{Participants and Procedure}

The sample for this cross-sectional study consisted of police officers from two English county forces. Officers of a Public Protection Unit $(n=714)$ within Force A and officers across four departments (Crime Investigation, Public Protection Unit, Response, Sexual 
Offences and Domestic Abuse Investigation) $(n=1,830)$ in Force B were invited to complete an online survey. An email was sent to the occupational account of eligible officers including a description of the purpose of the study and ethical rights associated with participation, in addition to a hyperlink to the survey and a letter of endorsement from the Police Federation of England and Wales (the representative body for police officers of constable, sergeant, and inspector rank). The survey was available for three weeks and a weekly reminder email was issued. Participation was voluntary and anonymous. The relevant Police Federation Joint Branch Boards granted approval for the study that adhered to the British Psychological Society's (2014) Code of Human Research Ethics.

\section{Measures}

Alcohol consumption: The 3-item Alcohol Use Disorders Identification Test Consumption (AUDIT-C) (Bush et al., 1998) was used to assess frequency and quantity of alcohol consumption, taking the previous year as the reference period. The items and response options are shown in Table 2. A sum score for the scale was calculated with possible scores ranging from $0-12$.

Hazardous alcohol consumption, defined as "a pattern of alcohol consumption that increases the risk of harmful consequences for the user or others" (Barbor et al., 2011: 5), was identified by an AUDIT-C score of $\geq 5$. This threshold has been widely used for the identification of hazardous alcohol consumption in high stress occupational groups, including US police officers (Violanti et al., 2011), US firefighters (Piazza-Gardner et al., 2014), German hospital doctors (Rosta, 2008), and UK veterinary surgeons (Bartram et al., 2009). In addition, this approach permitted comparisons with the civilian general population; the $\geq 5$ threshold offered the greatest sensitivity and specificity for the identification of hazardous alcohol consumption among English male adults (Foxcroft et al., 2015) and is widely used in UK general population research (e.g., Britton et al., 2020). 
Harmful alcohol consumption, defined as "alcohol consumption that results in consequences to physical and mental health" (Barbor et al., 2011: 5), was identified by an AUDIT-C score of $\geq 8$. We refer throughout this manuscript to probable harmful alcohol consumption owing to the unavailability of police-specific AUDIT-C validation data. A large-scale study of 3,720 UK adults seeking support for reducing alcohol consumption found that this threshold maximised sensitivity and specificity of the AUDIT-C for detecting drinking $\geq 14$ units of alcohol per week for females and 21 units for men (Khadjesari et al., 2017). Further, first responder research, albeit beyond the UK, found that a cut-off of $\geq 7.5$ offered the best identification of alcohol use disorder and $\geq 8.5$ the best identification of alcohol dependence (Jeong et al., 2017).

Importantly, the hazardous and probable harmful alcohol consumption thresholds that we applied were consistent with those used in research involving UK military samples against which we sought to compare prevalence rates observed in our study (Aguirre et al., 2014; Henderson et al., 2009; Whybrow et al., 2016). These studies applied the $\geq 8$ threshold to maximise the measure's sensitivity in recognition of high rates of alcohol consumption in military samples. In the absence of previous UK police studies, research involving UK military samples provides a useful point of comparison since these groups share characteristics such as a long-standing culture of alcohol consumption (Davey et al., 2000b; Lindsay and Shelley, 2009; Verrall, 2011), firmly embedded hierarchical organisational structures that dictate interactions across ranks, and close bonds among personnel.

Organisational job stressors: Following previous UK police stress research (Galbraith et al., 2021; Houdmont et al., 2012) the 35-item version of the UK Health and Safety Executive's Management Standards Indicator Tool (Health and Safety Executive, n.d.) was used to measure exposure to seven dimensions of the psychosocial work environment that, if not properly managed, can lead to harm to employees and organisations. Responses to the 
first 23 items are given on a 5-point scale of never (1), seldom (2), sometimes (3), often (4), and always (5), with positively framed items (e.g., 'I am clear what is expected of me at work') reverse scored so that high scores indicated high stressor exposure. Responses to the remaining items are given on a 5-point scale of strongly disagree (1), disagree (2), neutral (3), agree (4), and strongly agree (5), with positively framed items (e.g., 'staff are always consulted about change at work') reverse scored. To facilitate analyses examining the odds of hazardous and probable harmful alcohol consumption associated with high stressor exposure, responses were dichotomised with the two lowest exposure responses (e.g., never and seldom) indicating low stressor exposure and the two highest exposure responses (e.g., often and always) indicating high stressor exposure.

Covariates: Age, rank, departmental tenure, and years of police service were assessed as potential confounding variables. Data on gender were collected to enable separate analyses for males and females.

\section{Analytical Approach}

Analyses were stratified by gender in view of previous research having shown significant differences between female and male UK police officers on alcohol consumption and links between consumption and stressor exposures (Ménard and Arter, 2014). Descriptive statistics ( $n$ and \%) were generated for alcohol consumption at the AUDIT-C item level and the hazardous alcohol consumption (AUDIT-C sum score $\geq 5$ ) and probable harmful alcohol consumption (AUDIT-C sum score $\geq 8$ ) thresholds (Aim 1). To examine associations between job stressor exposure and alcohol consumption (Aim 2) we first applied independent $t$-tests to identify significant differences on the mean AUDIT-C sum score between high job stressor exposure and low job stressor exposure groups on each job stressor. Analyses were restricted to respondents who reported that they drank alcohol. Stressors for which there was a significant difference between groups were included in regression analyses. Binary logistic 
regression with $99 \%$ confidence intervals was used to estimate odds ratios for hazardous and probable harmful alcohol consumption associated with high job stressor exposure relative to low job stressor exposure. Covariates that significantly correlated with the AUDIT-C sum score were controlled for in regression analyses. Statistical significance was defined as $p<$ .01 throughout in view of the large sample size and multiple comparisons computed. Analyses were performed in SPPS Version 24.

\section{Results}

\section{Participant Characteristics}

A total of 1,226 respondents completed the survey. The response rate ranged across surveyed departments from $45 \%$ to $63 \%$, with an overall rate of $48 \%(N=1226 / 2544)$. After deletion of cases containing missing data, analyses were applied to a final sample of 1,200 cases. Participant characteristics are shown in Table 1. Our sample was broadly representative of the nationwide police officer workforce at the time of data collection. In terms of rank, constables and sergeants comprised respectively $81 \%$ and $16 \%$ of our sample compared to $77 \%$ and $15 \%$ of the total English and Welsh policing population (Home Office Statistics, 2015). Females were over-represented in our sample relative to the nationwide rate (41\% vs. $28 \%$ ). This disparity is a reflection of two fifths of our sample belonging to policing roles disproportionately populated by females. These include sexual offences and domestic abuse investigation teams and public protection units dealing with child protection, neglect and abuse investigation, management of dangerous offenders, and protection of vulnerable adults.

[Insert Table 1 about here]

\section{Frequency and Quantity of Alcohol Consumption}

Alcohol consumption rates stratified by gender are shown in Table 2. Alcohol abstinence was reported by $6 \%$ of respondents. The association between gender and 
abstinence was not significant $\left(\chi^{2}=3.04, d f=1, p=.08, \Phi=.05\right)$. Among those who consumed alcohol, approximately half of male and female respondents reported drinking alcohol at least 2-3 times per week ( $51 \%$ vs $49 \%$ ), with no significant difference by gender $\left(\chi^{2}=.06, d f=1, p=.80, \Phi=.01\right)$. On days they were drinking, a significantly greater proportion of males reported consuming at least five drinks $(16 \%$ vs $10 \%)\left(\chi^{2}=8.28, d f=1\right.$, $p<.01, \Phi=.09$ ). Likewise, a significantly greater proportion of males reported binge drinking $(76 \%$ vs $69 \%)\left(\chi^{2}=7.85, d f=1, p<.01, \Phi=.08\right)$; males were also significantly more likely to binge drink more frequently, with $13 \%$ binge drinking at least weekly compared to $7 \%$ of females $\left(\chi^{2}=9.34, d f=1, p<.01, \Phi=.09\right)$. Among respondents who consumed alcohol, $32 \%$ of females and $44 \%$ of males scored above the hazardous consumption threshold. The association between gender and hazardous consumption was significant $\left(\chi^{2}=15.62, d f=1, p<.001, \Phi=.12\right)$. Eleven per cent of males and $5 \%$ of females scored above the probable harmful consumption threshold. The association between gender and probable harmful consumption was significant $\left(\chi^{2}=11.86, d f=1, p<.001, \Phi=.10\right)$. [Insert Table 2 about here]

\section{Associations between Job Stressors and Alcohol Consumption}

Relations between alcohol consumption and job stressor exposure are shown in Table 3. A significant difference in the mean AUDIT-C sum score between high and low stressor exposure groups was observed in males on eight of the 35 Management Standards Indicator Tool items within the job control, work relationships, and role clarity domains. No significant differences were observed for females. Unadjusted binary logistic regression analyses were performed since none of the covariates demonstrated a significant correlation with alcohol consumption. Among males, the odds of hazardous alcohol consumption were significantly elevated for those who reported never or seldom being "clear about the goals and objectives for my department" (OR, 2.06; 99\% CI, 1.11-3.81). The odds of probable harmful alcohol 
consumption among males were significantly elevated - at least doubled - by high exposure to six job stressors, two from each of the job control, work relationships, and role clarity domains.

[Insert Table 3 about here]

\section{Discussion}

\section{Summary of Findings}

This study represents the first investigation among police officers in England concerning frequency and quantity of alcohol consumption and links with organisational job stressors. Female and male police officers did not significantly differ on alcohol abstinence and frequency of alcohol consumption. However, on days they were drinking alcohol males consumed significantly more; they were also significantly more likely to binge drink. Among those who drank alcohol, approximately one third of female and almost half of male officers reported hazardous alcohol consumption, while one in 20 female and one in 10 male officers reported probable harmful alcohol consumption. Job stressor exposure was not significantly associated with alcohol consumption among females. In males, high job stressor exposures from the Management Standards dimensions of job control, work relationships, and role clarity were significantly associated with probable harmful alcohol consumption.

\section{Findings Compared to the Literature}

The mean AUDIT-C alcohol consumption score observed in our study (4.3) was almost identical to that found among US emergency services personnel including police officers (4.2) and firefighters (4.1) (Piazza-Gardner et al., 2014; Violanti et al., 2011). A significantly higher proportion of males than females reported hazardous and probable harmful alcohol consumption. The significantly higher rate observed among males is consistent with previous small-scale research involving UK police officers (Ménard and Arter, 2014), yet the extent to which the rates of hazardous and probable harmful alcohol 
consumption are reflective of the wider UK policing population remains unclear. Some contextualisation can be obtained by comparing our findings to the UK military, which is similarly characterised by a long-standing culture of alcohol consumption (Verrall, 2011), firmly embedded hierarchical organisational structures that dictate interactions across ranks, and close bonds among personnel. For alcohol abstinence, rates observed in our study (females, $8 \%$; males, 5\%) were higher than found in UK military samples, where rates of $\leq 2 \%$ have been observed (Aguirre et al., 2014; Henderson et al., 2009). Abstinence rates observed in our study were notably similar to those in another occupational role widely regarded as involving high levels of stress, that of veterinary surgeon: one large-scale study of UK veterinary surgeons found an abstinence rate of $7 \%$ (females) and $4 \%$ (males) (Bartram et al., 2009). Higher abstinence rates are typically observed in the English adult population (females, 21\%; males, 15\%) (Craig et al., 2015).

Alcohol consumption in our sample was lower than found in the British armed forces. We observed hazardous alcohol consumption among $32 \%$ of female and $44 \%$ of male police officers and probable harmful consumption among $5 \%$ of females and $11 \%$ of males. In contrast, prevalence rates of $65 \%$ (hazardous) and $16 \%$ (probable harmful) were found during routine and discharge medicals across the Air Force, Army, and Navy (Aguirre et al., 2014). Similarly, probable harmful alcohol consumption prevalence rates of $12 \%$ (females) and $18 \%$ (males) have been observed in UK Royal Navy Personnel and Royal Marines, with the authors suggesting that these high rates might reflect the arduous operational environment and a response to being at sea for a prolonged period rather than personnel's normal state during pre- or post-deployment (Whybrow et al., 2016). An earlier study of UK Royal Navy personnel posted to warships identified a probable harmful alcohol consumption prevalence rate of 57\% (Henderson et al., 2009). The authors suggested the military environment might have contributed to this exceptionally high rate, with traditional ideas about group 
camaraderie and bonding, close-knit social interaction, and peer pressure exerting a causative influence. Such cultural factors were evident in UK policing during the twentieth century when end-of-shift drinking was an important part of police culture. However, they exert less influence in the modern era following the nationwide closure of most police station bars and changes in social attitudes towards alcohol consumption, which may help explain the lower consumption rates observed in our study.

The hazardous alcohol consumption rate observed in our study (females, 32\%; males, $44 \%$ ) is considerably higher than the $24 \%$ observed in the English adult population assessed during the same time period as our data collection (Brown et al., 2020). This disparity highlights the need for a focus on the development of practical interventions targeted at this occupational group. It also suggests that caution needs to be applied in generalising the US corpus of police alcohol consumption research to the UK context, given that US police officers do not consistently report elevated alcohol consumption relative to the general population (Lindsay, 2008) or other occupational groups (Weir et al., 2012). In this way, the current study points to the need for a UK-specific strand of police alcohol research.

We found associations between job stressor exposure and alcohol consumption among male officers only. This accords with earlier multinational research involving UK police officers in which critical incident exposure and social stressors showed small yet significant correlations with alcohol consumption among males only (Ménard and Arter, 2014), as well as the large-scale Whitehall II study of London-based civil servants (Head et al., 2004). In our study, psychosocial work characteristics from the job control, work relationships, and role clarity Management Standards domains presented a significant risk for probable harmful alcohol consumption. Within the control domain, lack of say over speed of work and the way it is done were associated with threefold increased odds of probable harmful alcohol consumption. The pre-eminence of job control - and absence of links 
between job demands and alcohol consumption - is consistent with Whitehall II (Head et al., 2004) and Australian policing research in which job control, but not job demands, was significantly linked to alcohol dependency (Davey et al., 2000b). Davey and colleagues acknowledged that their single-item measure of global job control prevented in-depth interpretation and suggested that further research examining linkages between specific aspects of job control and alcohol consumption could usefully point the way towards intervention targets. Our findings suggest a focus on speed of work and choice over how work is done.

\section{Practical Implications}

High levels of alcohol consumption may have serious consequences for police officers, their organisations, and the communities they serve. Our findings indicate a worrying prevalence of probable harmful alcohol consumption among male officers, with one in 10 reporting an AUDIT-C score $\geq 8$. A score at or above this threshold can be produced by multiple permutations of frequency and quantity of alcohol consumption. Yet, to put this rate of consumption in context, it is worth considering that a score at this threshold may involve a pattern of drinking alcohol at least four times per week, with three or four drinks consumed on each occasion, and six or more drinks consumed on a single occasion weekly. Though we did not distinguish between alcohol consumption on days of work and non-work, it is probable that alcohol consumption at this level has implications for work effectiveness.

These findings suggest that action is required to reduce alcohol consumption in English police officers, with a particular focus on probable harmful consumption among males. The findings point towards modification of the psychosocial work environment as a mechanism for reduction of probable harmful alcohol consumption in this group. Notably, the eight job stressors associated with significantly elevated odds of probable harmful alcohol consumption are potentially modifiable without extensive financial investment. Job stressors 
within the work relationships and role clarity domains that demonstrated significant linkages with probable harmful alcohol consumption could be addressed through interventions centred on improving peer-to-peer working relationships and clarification of departmental goals and objectives and the ways in which these contribute to overall organisational aims. Job stressors within the control domain, concerning speed of work and the way in which it is done, might be more difficult to address in a policing context and require innovative solutions.

The police station context offers an opportunity for brief interventions to promote reductions in alcohol consumption, particularly for hard-to-reach groups that rarely visit a general practitioner, such as young males. Since male police officers in our sample carried the burden of probable harmful alcohol consumption, localised health promotion activities targeted on reducing alcohol consumption among males might be beneficial.

\section{Limitations and Further Research}

The strengths of this study lie in the use of established measurement instruments and large participant sample. Nevertheless, some methodological limitations must be acknowledged. Cross-sectional research designs make an important contribution to the exploration of new ideas owing to efficiencies in time and funding requirements and an ability to demonstrate the existence of relationships between variables, which itself is a crucial first step towards establishing a causal link (Spector, 2019). Nevertheless, they are limited by an inability to detect causal relations between variables. We suggest a causal order of the study variables whereby exposure to job stressors leads to alcohol consumption, yet it is possible that associations could result from reverse causality, whereby elevated (probable harmful) alcohol consumption influences psychosocial work environment perceptions, or reciprocal relationships. Future studies involving retrospective reports (to help establish the temporal order of variables), alternative sources of data (e.g., clinical interview data 
concerning alcohol consumption) or longitudinal or diary designs could help to definitively establish the causal direction of these relationships.

Exploratory studies concerning neglected topics are typically restricted in scale. This ensures efficient use of resources at a point in the unfolding research process when questions remain as to whether the new line of research is likely to bear fruit. In accordance with this approach, the current preliminary exploration of alcohol consumption and links with organisational job stressor exposures in UK policing involved officers drawn from two forces, both of which are located in England and one of which is primarily rural, possibly leading to under-representation of officers policing urban environments. Our sample also involved over-representation of females and focused on a restricted set of policing roles. As such, these initial findings offer a tentative indication of the wider prevalence of alcohol consumption; large scale replication is required to draw definitive conclusions on alcohol consumption rates across UK policing. Nationally representative replication studies might also present an opportunity for police-specific validation of the AUDIT-C instrument as a screener for probable harmful alcohol consumption. AUDIT-C validation studies have demonstrated the need for population-specific cut-off scores to maximise its diagnostic efficiency (e.g., Crawford et al., 2013; Foxcroft et al., 2013; Khadjesari et al., 2017), yet there is an absence of evidence for UK police officers. Research involving administration of the AUDIT-C alongside a reference standard would permit identification of the optimum cut-off scores required to maximise sensitivity and specificity in relation to hazardous and probable harmful alcohol consumption in this occupational context. Our findings indicate that screening for alcohol consumption problems in this occupational sector would facilitate identification of at-risk individuals, enabling them to be referred for tailored intervention. The availability of police-specific AUDIT-C validation data is a necessary precondition for such a programme of screening. 


\section{Conclusion}

In conclusion, the current study has offered an initial insight into the frequency and quantity of alcohol consumption in English police officers and linkages with organisational job stressor exposures. In this way it has demonstrated a need for nationally representative research that facilitates identification of at-risk groups while providing an empirical foundation for psychosocial work environment modifications to ameliorate problematic alcohol consumption.

\section{References}

Agnew R (1992) Foundation for a general strain theory of crime and delinquency. Criminology 31(1): 47-87.

Aguirre M, Greenberg N, Sharpley J et al. (2014) Alcohol consumption in the UK armed forces: Are we drinking too much? BMJ Military Health 160(1): 72-73.

Ahern E, Sadler L, Lamb M and Gariglietti G (2017) Wellbeing of professionals working with suspected victims of child sexual exploitation. Child Abuse Review, 26(2): 130140.

Anderson P (2012) Alcohol and the workplace. In: Anderson P, Møller L and Galea G (eds) Alcohol in the European Union: Consumption, harm and policy approaches. Geneva: World Health Organization, pp. 69-82.

Barbor T, Higgins-Biddle J, Saunders J et al. (2001) The Alcohol Use Disorders Identification Test: Guidelines for use in Primary Care ( $2^{\text {nd }}$ ed). Geneva: World Health Organization.

Bartram D, Sinclair J and Baldwin D (2009) Alcohol consumption among veterinary surgeons in the UK. Occupational Medicine, 59(5): 323-326.

British Psychological Society (2014). Code of Human Research Ethics. Leicester: British Psychological Society. 
Britton A, Fat L and Neligan A (2020) The association between alcohol consumption and sleep disorders among older people in the general population. Scientific Reports 10(1): $1-7$.

Brookes K, Limbert C, Deacy C et al. (2013) Systematic review: work-related stress and the HSE management standards. Occupational Medicine 63(7): 463-472.

Brown F, Fielding J and Grover J. (1999) Distinguishing traumatic, vicarious and routine operational stressor exposure and attendant adverse consequences in a sample of police officers. Work \& Stress 13(4): 312-325.

Brown J, Kock L, Kale D et al. (2020) September 20: Trends on alcohol consumption in England from the Alcohol Toolkit Study. Available at http://www.alcoholinengland.info/latest-stats (Accessed 26 February 2021).

Bush K, Kivlahan D, McDonell M et al. (1998) The AUDIT alcohol consumption questions (AUDIT-C): An effective brief screening test for problem drinking. Archives of Internal Medicine 158(16): 1789-1795.

Carleton, R, Afifi T, Taillieu T et al. (2020) Assessing the relative impact of diverse stressors among public safety personnel. International Journal of Environmental Research and Public Health, 17(4): 1234.

Chan J and Anderson J (2020) Influence of organizational stressors on reported depressive symptoms among police. Occupational Medicine 70(7): 496-502.

Collins P and Gibbs A (2003) Stress in police officers: a study of the origins, prevalence and severity of stress-related symptoms within a county police force. Occupational Medicine 53(4): 256-264.

Craig R, Fuller E and Mindell J (2015) Health Survey for England 2014: Vol 1: Health, Social Care and Lifestyles. Leeds: Health and Social Care Information Centre. 
Crawford E, Fulton J, Swinkels C et al. (2013) Diagnostic efficiency of the AUDIT-C in U.S. veterans with military service since September 11, 2001. Drug and Alcohol Dependence 132(1-2): 101-106.

Davey J, Obst P and Sheehan M (2000a) The use of AUDIT as a screening tool for use in the police work-place. Drug and Alcohol Review 19(1): 49-54.

Davey J, Obst P and Sheehan M (2000b) Work demographics and officers' perceptions of the work environment which add to the prediction of at risk alcohol consumption within an Australian police sample. Policing: An International Journal of Police Strategies and Management 23(1): 69-81.

Edwards A and Kotera Y (2020) Mental health in the UK police force: A qualitative investigation into the stigma with mental illness. International Journal of Mental Health Addiction. Epub ahead of print 15 January 2020. DOI: 10.1007/s11469-01900214-x.

Foxcroft D, Smith L, Thomas H et al. (2015) Accuracy of Alcohol Use Disorders Identification Test for detecting problem drinking in 18-35 year-olds in England: Method comparison study. Alcohol and Alcoholism 50(2): 244-250.

Galbraith N, Boyda D, McFeeters D et al. (2021) Patterns of occupational stress in police contact and dispatch personnel: Implications for physical and psychological health. International Archives of Occupational and Environmental Health 94: 231-241.

Gibson C, Swatt M and Jolicoeur J (2001) Assessing the generality of general strain theory: The relationship among occupational stress experienced by male police officers and domestic forms of violence. Journal of Crime and Justice 24(2): 29-57.

Goh J, Pfeffer J and Zenios S (2015). Workplace stressors and health outcomes: Health policy for the workplace. Behavioral Science and Policy 1(1): 43-52. 
Griswold M, Fullman N, Hawley C et al. (2018) Alcohol use and burden for 195 countries and territories, 1990-2016: A systematic analysis for the Global Burden of Disease Study 2016. Lancet 392: 1015-1035.

Head J, Stansfeld S and Siegrist J (2004) The psychosocial work environment and alcohol dependence: a prospective study. Journal of Occupational and Environmental Medicine 61(3): 219-224.

Health and Safety Executive (n.d.) HSE Management Standards Indicator Tool. Available at: https://www.hse.gov.uk/stress/assets/docs/indicatortool.pdf (accessed 26 February 2021).

Henderson A, Langston V and Greenberg N (2009) Alcohol misuse in the Royal Navy. Occupational Medicine 59(1): 25-31.

Houdmont J, Kerr R and Randall R (2012) Organisational psychosocial hazard exposures in UK policing: Management Standards Indicator Tool reference values. Policing: An International Journal of Police Strategies and Management 35(1): 182-197.

Home Office Statistics (2015) Police workforce, England and Wales: 31 March 2015.

Available at: https://www.gov.uk/government/statistics/police-workforce-englandand-wales-31-march-2015 (accessed 26 February 2021).

Hurrell A-K, Draycott S and Andrews L (2018) Secondary traumatic stress in police officers investigating childhood sexual abuse. Policing: An International Journal 41(5): 636650.

Jeong H, Park S, Lim S et al. (2017) Psychometric properties of the Alcohol Use Disorders Identification Test-Consumption (AUDIT-C) in public first responders Substance Use and Misuse 52(8): 1069-1075.

Khadjesari Z, White I, McCambridge J et al. (2017) Validation of the AUDIT-C in adults seeking help with their drinking online. Addiction Science and Clinical Practice 
12(1): 2 .

Lindsay V (2008) Police officers and their alcohol consumption: Should we be concerned? Police Quarterly 11(1): 74-87.

Lindsay V and Shelley K (2009) Social and stress-related influences of police officers' alcohol consumption. Journal of Police Criminal Psychology 24(2): 87-92.

McCreary D and Thompson M (2006) Development of two reliable and valid measures of stressors in policing: The operational and organizational police stress questionnaires. International Journal of Stress Management 13(4): 494-518.

McFarlin S and Fals-Stewart W (2002) Workplace absenteeism and alcohol use: A sequential analysis. Psychology of Addictive Behavior 16(1): 17-21.

Mackay C, Cousins R, Kelly P et al. (2004) 'Management Standards' and work-related stress in the UK: Policy background and science. Work \& Stress 18(2): 91-112.

Mangione T, Howland J, Amick B et al. (1999) Employee drinking practices and work performance. Journal of Studies on Alcohol 60(2): 261-271.

Ménard K and Arter M (2014) Stress, coping, alcohol use, and posttraumatic stress disorder among an international sample of police officers: Does gender matter? Police Quarterly 17(4): 307-327.

Ménard K, Arter M and Khan C (2016) Critical incidents, alcohol and trauma problems, and service utilization among police officers from five countries. International Journal of Comparative and Applied Criminal Justice 40(1): 25-42.

Piazza-Gardner A, Barry A, Chaney E et al. (2014) Covariates of alcohol consumption among career firefighters. Occupational Medicine 64(8): 580-582.

Piquero N (2005) Understanding police stress and coping resources across gender: A look toward general strain theory. In: Copes H (ed) Policing and stress. Upper Saddle River, NJ: Prentice Hall, pp. 126-139. 
Ragland D, Krause N and Greiner B (2002) Alcohol consumption and incidence of workers' compensation claims: A 5-year prospective study of urban transit operators. Alcohol Clinical and Experimental Research 26(9): 1388-94.

Rosta, J (2008) Hazardous alcohol use among hospital doctors in Germany. Alcohol and Alcoholism 42(2): 198-203.

Salonsalmi A, Rahkonen O, Lahelma E et al. (2015) Changes in alcohol drinking and subsequent sickness absence. Scandinavian Journal of Public Health 43(4): 364-372.

Spector P (2019) Do not cross me: optimizing the use of cross-sectional designs. Journal of Business and Psychology 34(2): 125-137.

Swatt M, Gibson C and Piquero N (2007) Exploring the utility of general strain theory in explaining problematic alcohol consumption by police officers. Journal of Criminal Justice 35(6): 596-611.

Syed S, Ashwick R, Schlosser M et al. (2020) Global prevalence and risk factors for mental health problems in police personnel: A systematic review and meta-analysis. Occupational and Environmental Medicine 77(11): 737-747.

The Royal Foundation (2020) Assessing the mental health and wellbeing of the emergency responder community in the UK. Available at: https://kcmhr.org/erreport2020mentalhealth-wellbeing/ (accessed 26 February 2021).

Upmark M, Moller J and Romelsjo A (1999) Longitudinal, population-based study of self reported alcohol habits, high levels of sickness absence, and disability pensions. Journal of Epidemiology and Community Health 53(4): 223-229.

Verrall N (2011) A review of military research into alcohol consumption. BMJ Military Health 157(2): 164-169.

Violanti J (2017) Police stressors and health: A state of the art review. Policing: An International Journal of Police Strategies and Management 40(4): 642-656. 
Violanti J, Slaven J, Charles L et al. (2011) Police and alcohol use: A descriptive analysis and associations with stress outcomes. American Journal of Criminal Justice 36(4): 344356.

Violanti J, Marshall J and Howe G (1985) Stress, coping and alcohol use: the police connection. Journal of Police Science and Administration 13(2): 106-110.

Weir H, Stewart D and Morris R (2012) Problematic alcohol consumption by police officers and other protective service employees: A comparative analysis. Journal of Criminal Justice 40(1): 72-82.

Whybrow D, Jones N, Evans C et al. (2016) The mental health of deployed UK maritime forces. Occupational and Environmental Medicine 73(2): 75-82.

Yasin Y, and Banoub J (2018) GBD 2016 Alcohol Collaborators. Alcohol use and burden for 195 countries and territories, 1990-2016: a systematic analysis for the Global Burden of Disease Study 2016. Lancet 392: 1684-735. 
Table 1

Participant Characteristics

\begin{tabular}{llll}
\hline & Female $(N=493)$ & Male $(N=707)$ & Total $(N=1,200)$ \\
\hline Age & \multicolumn{3}{c}{$\mathrm{M}(S D)$} \\
Years of police service & $39.65(7.13)$ & $42.56(7.42)$ & $41.36(7.44)$ \\
Years in current department & $13.54(6.71)$ & $15.44(6.98)$ & $14.66(6.93)$ \\
\hline & $4.68(4.25)$ & $5.76(4.93)$ & $5.32(4.69)$ \\
\hline Rank & \multicolumn{3}{c}{$N(\%)$} \\
$\quad$ Constable & $421(85.4)$ & $545(77.1)$ & $966(80.5)$ \\
$\quad$ Sergeant & $56(11.4)$ & $131(18.5)$ & $187(15.6)$ \\
$\quad$ Inspector or above & $16(3.2)$ & $31(4.4)$ & $47(3.9)$ \\
Department & $136(27.6)$ & $356(50.4)$ & $492(41.0)$ \\
$\quad$ Response & $31(6.3)$ & $30(4.2)$ & $61(5.1)$ \\
$\quad$ Sexual offences and domestic abuse & & $144(20.4)$ & $211(17.6)$ \\
$\quad$ investigation & $67(13.6)$ & $177(25.0)$ & $436(36.3)$ \\
$\quad$ Crime investigation & $259(52.5)$ & & \\
$\quad$ Public protection unit &
\end{tabular}


Table 2

Frequency and Quantity of Alcohol Consumption (AUDIT-C), Stratified by Gender

\begin{tabular}{llll}
\hline Item & Female & Male & Total \\
\hline \multicolumn{4}{c}{$N(\%)$} \\
\hline How often do you have a drink containing alcohol? \\
Never (0) & $38(7.7)$ & $37(5.2)$ & $75(6.3)$ \\
Monthly or less (1) & $104(21.1)$ & $135(19.1)$ & $239(19.9)$ \\
$2-4$ times a month (2) & $110(22.3)$ & $175(24.8)$ & $28523.8)$ \\
$2-3$ times a week (3) & $182(36.9)$ & $250(35.4)$ & $43236.0)$ \\
$\geq 4$ times a week (4) & $59(12.0)$ & $110(15.6)$ & $169(14.1)$ \\
How many drinks containing alcohol do you have on a typical day when you are drinking? ${ }^{\text {a }}$ \\
1 or 2 (0) & $264(58.0)$ & $320(47.8)$ & $584(51.9)$ \\
3 or 4 (1) & $145(31.9)$ & $242(36.1)$ & $387(34.4)$ \\
5 or 6 (2) & $37(8.1)$ & $77(11.5)$ & $114(10.1)$ \\
7 to 9 (3) & $9(2.0)$ & $23(3.4)$ & $32(2.8)$ \\
$\geq 10(4)$ & - & $8(1.2)$ & $8(0.7)$ \\
How often do you have six or more drinks on one occasion? ${ }^{\text {a }}$ & & $303(26.9)$ \\
Never (0) & $143(31.4)$ & $160(23.9)$ & $466(41.4)$ \\
Less than monthly (1) $_{\text {Monthly (2) }}^{191(42.0)}$ & $275(41.0)$ & $236(21.0)$ \\
Weekly (3) & $88(19.3)$ & $148(22.1)$ & $112(10.0)$ \\
Daily or almost daily (4) & $32(7.0)$ & $80(11.9)$ & $8(0.7)$ \\
AUDIT-C $\geq 5^{\text {a }}$ & $1(0.2)$ & $7(1.0)$ & $470(39.2)$ \\
AUDIT-C $\geq 8^{\text {a }}$ & $158(32.0)$ & $312(44.1)$ & $93(8.3)$ \\
AUDIT-C, Mean (SD) ${ }^{\text {a }}$ & $22(4.8)$ & $71(10.6)$ & $4.29(2.07)$ \\
\hline
\end{tabular}

${ }^{a}$ Excludes respondents who did not drink alcohol $(N=75)$ 
Table 3

Binary Logistic Regression for Organizational Job Stressors and Alcohol Consumption in Male Police Officers

\begin{tabular}{|c|c|c|c|c|c|}
\hline \multirow[t]{4}{*}{ Job Stressor } & AUDIT-C Sum, & \multirow{2}{*}{\multicolumn{2}{|c|}{$\begin{array}{l}\text { AUDIT-C Sum, } \\
\text { High Stressor }\end{array}$}} & \multirow{2}{*}{$\begin{array}{l}\text { Hazardous } \\
\text { Alcohol }\end{array}$} & \multirow{3}{*}{$\begin{array}{l}\text { Probable Harmful } \\
\text { Alcohol } \\
\text { Consumption } \\
\text { (AUDIT-C } \geq 8 \text { ) }\end{array}$} \\
\hline & Low Stressor & & & & \\
\hline & Exposure & Exposure & & Consumption & \\
\hline & $N, M(S D)$ & $N, M(S D)$ & $t$ & OR $(99 \% \mathrm{CI})$ & OR $(99 \% \mathrm{CI})$ \\
\hline \multicolumn{6}{|l|}{ Control } \\
\hline I have some say over the way I work ${ }^{c}$ & $339,4.30(2.07)$ & $152,5.14(2.59)$ & $-3.512 * *$ & $1.65(0.99-2.74)$ & $3.20(1.57-6.54)^{* *}$ \\
\hline I have a say in my own work speed ${ }^{\text {a }}$ & $132,4.02(1.99)$ & $290,4.80(2.37)$ & $-3.294 * *$ & $1.56(0.90-2.70)$ & $2.92(1.05-8.16)^{*}$ \\
\hline \multicolumn{6}{|l|}{ Relationships } \\
\hline There is friction or anger between colleagues ${ }^{b}$ & $219,4.29(2.01)$ & $181,4.86(2.24)$ & $-2.653^{*}$ & $1.49(0.88-2.50)$ & $2.49(1.04-5.94)^{*}$ \\
\hline Relationships at work are strained $^{\mathrm{d}}$ & $182,4.04(1.99)$ & $288(4.74(2.29)$ & $-3.481 * *$ & $1.59(0.97-2.60)$ & $2.86(1.11-7.34)^{*}$ \\
\hline \multicolumn{6}{|l|}{ Role } \\
\hline I am clear what is expected of me at work ${ }^{a}$ & $501,4.36(2.10)$ & $34,5.47(2.69)$ & $-2.929 *$ & $2.05(0.80-5.23)$ & $2.17(0.64-7.40)$ \\
\hline I am clear what my duties and responsibilities are ${ }^{a}$ & $507,4.29(2.12)$ & $32,5.88(2.62)$ & $-4.048 * *$ & $2.61(0.98-7.01)$ & $2.88(0.89-9.29)$ \\
\hline I am clear about the goals and objectives for my department ${ }^{a}$ & $377,4.35(2.12)$ & $91,5.31(2.55)$ & $-3.325 * *$ & $2.06(1.11-3.81)^{*}$ & $3.14(1.40-7.08)^{* *}$ \\
\hline $\begin{array}{l}\text { I understand how my work fits into the overall aim of the } \\
\text { organisation }^{\text {a }}\end{array}$ & $353,4.27(2.09)$ & $93,5.02(2.52)$ & $-2.930 *$ & $1.49(0.81-2.71)$ & $3.15(1.33-7.46)^{* *}$ \\
\hline
\end{tabular}

$* \mathrm{p}<.01, * * \mathrm{p}<.001$

${ }^{a}$ never/seldom vs often/always (reference category)

${ }^{\mathrm{b}}$ often/always vs never/seldom (reference category)

${ }^{\mathrm{c}}$ strongly disagree/disagree vs agree/strongly agree (reference category)

$\mathrm{d}$ agree/strongly agree vs strongly disagree/disagree (reference category) 